\title{
Experimental Testing of the DL Model within the System of Lifelong Education of Primary School Teachers
}

Oleksii Mukoviz

Prof., Theory of Primary Education Chair, Pavlo Tychyna Uman State Pedagogical University, Uman, Ukraine Corresponding author, alexsmukovoz@gmail.com

Natalia Kolomiiets

Assoc. Prof., Education Technologies and Pedagogical Creativity Chair, Pavlo Tychyna Uman State Pedagogical University, Uman, Ukraine

\begin{abstract}
The article presents the results of testing of the distance learning model in the system of lifelong education of primary school teachers, namely the proofs of the effectiveness of the technology of training of distance learning tutors (organizers) of higher education institutions of III-IV accreditation levels and the ways of forming of primary school teachers' readiness to distance learning in lifelong education. The analysis of the results of the experiment showed that the majority of respondents reached the highest level of readiness to distance learning in lifelong education. According to the results of statistical processing of the participants' questionnaires, a significant increase of all parameters of level indicators is stated.
\end{abstract}

Keywords: distance learning (DL), tutor, lifelong education of primary school teachers

\section{INTRODUCTION}

At the present-day stage of economic relations development, modernization processes in the higher education of Ukraine are oriented towards international integration globalization, democratization and humanization. Modern information society of a comprehensively developed state requires that higher educational institutions train professionals able to learn distantly within the context of lifelong education.

The necessity to implement modern information technologies in education is determined by the fact that, in this day and age, a primary school teacher needs to educate themselves lifelong, which gave rise to new opportunities for lifelong learning. Lifelong education is largely associated with DL technologies, i.e. with the implementation of internet technologies, which, in their turn, open up vast opportunities for efficient personality-centered learning. Therefore, the issue of primary school teachers' preparedness for DL within the system of lifelong education is of particular relevance.

The results of the research and publications analysis attested to the fact that the matter of student preparedness for DL in educational institutions has always been an issue researched by Valerii Bykov (Bykov, 2008), Serhii Semerikov, Ivan Teplytskyi, Svitlana Shokaliuk (Semerikov, Teplytskyi \& Shokaliuk, 2008), Liubov Kartashova (Kartashova, 2011), Volodymyr Kukharenko (Kukharenko, 2012), Oleksandr Spivakovskyi, Mykhailo Lvov, Henadii Kravtsov (Spivakovskyi, Lvov \& Kravtsov, 2009), Oleh Spirin, Kateryna Kolos (Spirin \& Kolos, 2011) and others.. However, insufficiently studied remains the issue of primary school teachers' preparedness for DL within the system of lifelong education.

Citation: Mukoviz, O., \& Kolomiiets, N. (2018). Experimental Testing of the DL Model within the System of Lifelong Education of Primary School Teachers. Anatolian Journal of Education, 3(2), 63-74. https://doi.org/10.29333/aje.2018.326a 
Article Objective: to experimentally test the efficiency of the DL model within the system of lifelong education of primary school teachers.

\section{METHOD}

We undertook the research of the training of primary school teachers on the use of DL technologies within the system of lifelong education in the framework of teacher's training higher educational institutions.

In the process of developing an efficient system of forming primary school teachers' preparedness for DL within the system of lifelong education, we have established the following stages of experimental verification of the core conclusions of our work:

I: Identifying stage, at which the levels of primary school teachers' preparedness for DL within the system of lifelong education were studied

II: Formative stage, at which the efficiency of the author's DL model within the system of lifelong education of primary school teachers was tested

III: Analysis of the outcomes of implemented the designed learning model.

These stages do not have rigid boundaries, given that it is not possible to mark limits within a single process and to establish its joining nexuses: where does education start and attitudes continue, and where the latter transition into the domain of will and action. However, each stage requires respective content, as well as organizing and teaching arrangement.

The design of the DL model in lifelong education of elementary school teachers (O. P. Mukoviz, 2014c) builds on a certain number of necessary structural elements of professional training and teacher's personality traits by way of stimulating in a teacher already formed potential characteristics and taking them to a desired level.

At the experimental stage of research, not only the model was implemented as a holistic system of making elementary school teachers prepared for DL in lifelong education system, but also the process, the nature of the developed of the core formation components was traced. Essential was work on identifying and theoretical substantiation of material connections between transformations in content, forms and organizing methods of professional educator training on the one hand and the outcomes of elementary school teachers' practical work, the dynamic of the acquisition of professional skills to perform DL in lifelong education system, on the other hand.

Based on the results of the pedagogic experiment, its efficiency was assessed, necessary adjustment was introduced, experimental material was generalized, comparative analysis was performed, and inferences were drawn.

The logic of the research secured consistent progress of our scientific search from a hypothetical idea of the ways of preparing elementary school teachers for DL in lifelong education system towards modeling the process as a holistic system, the experimental verification of which presupposed theoretical conclusions and practical recommendations.

In our previous research, the status of primary school teachers' preparedness for DL within the system of lifelong education was checked:

Components of primary school teachers' preparedness for DL within the system of lifelong education were identified and substantiated (motivation and value, cognitive and operational) (O. P. Mukoviz, 2015). 
Levels of primary school teachers' preparedness for DL within the system of lifelong education were identified and substantiated (low, average, sufficient, high) (O. P. Mukoviz, 2015).

The status of teachers' preparedness for tutor activities in higher educational institutions of 3rd-3th accreditation levels was checked (O. P. Mukoviz, 2015).

The status of primary school teachers' preparedness for DL within the system of lifelong education was checked (O. P. Mukoviz, 2016).

However, one of the key objectives of our research is to experimentally test the efficiency of the DL model within the system of lifelong education of primary school teachers.

\section{FINDINGS}

At this stage of research, the training of qualified teachers was conducted within the period from January 20 to June 21, 2015 at the Central Post-Diploma Pedagogic Education Institute of the Education Management University of the National Academy of Pedagogic Sciences of Ukraine. 134 teachers of Pavlo Tychyna State Pedagogical University of Uman underwent career advancement training, 48 of which comprised our experiment group (EG) (they teach at the Elementary Education Department).

The training of tutor teachers (organizers) in DL within the higher educational institutions of 3rd-4th accreditation levels is detailed in publication (O. P. Mukoviz, 2014b).

In the control groups (CG), such activities were not undertaken.

In the training of tutor teachers (organizers) in DL within the higher educational institutions of 3rd-4th accreditation levels, it was also taken into account that they are higher educational institution teachers possessing life and professional experience. Therefore, in organizing career advancement training efforts, the specific features of andragogy (a branch of pedagogic dealing with the system and methodology of adult education).

The analysis of testing results has demonstrated that over, the career enhancement training period, teachers from the EG developed the following skills in the domain of organizing DL in higher educational institutions:

1) organizing skills: the ability to organize the DL of students;

2) information skills: the aptitude to develop distance learning curricula in the DL system;

3) communication skills: the ability to communicate with students within the DL system;

4) development skills: the ability to activate the cognitive activities of students in the DL system.

At the final stage of career advancement training, all EG teachers received a Teacher-Tutor (Organizer) in DL of Higher Educational Institutions certificate that entitles them to organize DL in the system of lifelong education of elementary school teachers.

To assess the performance of career advancement training under the Teacher-Tutor (Organizer) in DL of Higher Educational Institutions category, the constative experiment toolkit was employed (O. P. Mukoviz, 2015) and the maturity levels of teachers' preparedness for tutor activities in higher educational institutions of 3rd-4th accreditation level following the completion of the experiment were determined. Having received, as a result of the summary assessment, data regarding the changes in the maturity levels of the core elements of preparedness in EG and CG teachers, we have assessed the significance of these changes and drew inferences as regards the efficiency of the implementation of the given model. 
Thus, after the statistical processing of the experiment results based on the maturity levels of the elements of teachers' preparedness for tutor activities, we have come to be reassured of considerable achievements on the part of the EG. This is attested to by the consolidated experiment data presented in Table 1.

The above mentioned results, in terms of the motivational and value-based component, have shown that $4.17 \%$ of EG teachers lack a lasting cognitive interest in tutor activities at higher educational institutions of 3rd-4th accreditation level; these teachers do not understand the advantages that DL technologies deliver to them compared to traditional teaching methods. Moreover, they are not endeavoring to capitalize on modern opportunities of LD in organizing their professional activities. However, the number of teachers with the sufficient level of preparedness (EG $-66.66 \%$ compared to $6.25 \%$ in CG) and high level of preparedness (20.83\% in EG against $2.08 \%$ in CG) increased considerably.

Table 1

The status of teachers' preparedness for tutor activities by maturity levels (final assessment)

\begin{tabular}{|c|c|c|c|c|c|c|c|c|c|}
\hline \multirow{3}{*}{$\begin{array}{l}\text { Preparedness } \\
\text { Element }\end{array}$} & \multirow{3}{*}{$\begin{array}{l}\text { Preparedness } \\
\text { Levels }\end{array}$} & \multicolumn{4}{|c|}{ Experiment Group } & \multicolumn{4}{|c|}{ Control Group } \\
\hline & & \multicolumn{2}{|c|}{ BEFORE } & \multicolumn{2}{|c|}{ AFTER } & \multicolumn{2}{|c|}{ BEFORE } & \multicolumn{2}{|c|}{ AFTER } \\
\hline & & $\begin{array}{c}\text { q-ty in } \\
\%\end{array}$ & $\begin{array}{c}\text { absolute } \\
\text { q-ty }\end{array}$ & $\begin{array}{l}\text { q-ty } \\
\text { in } \%\end{array}$ & $\begin{array}{l}\text { absolute } \\
\text { q-ty }\end{array}$ & $\begin{array}{l}\text { q-ty } \\
\text { in \% }\end{array}$ & $\begin{array}{c}\text { absolute } \\
\text { q-ty }\end{array}$ & $\begin{array}{l}\text { q-ty } \\
\text { in } \%\end{array}$ & $\begin{array}{c}\text { absolute } \\
\text { q-ty }\end{array}$ \\
\hline \multirow{4}{*}{$\begin{array}{l}\text { Motivational } \\
\text { and Value- } \\
\text { Based }\end{array}$} & High & 4.17 & 2 & 20.83 & 10 & 2.08 & 1 & 2.08 & 1 \\
\hline & Sufficient & 6.25 & 3 & 66.66 & 32 & 6.25 & 3 & 6.25 & 3 \\
\hline & Average & 27.08 & 13 & 8.34 & 4 & 31.25 & 15 & 31.25 & 15 \\
\hline & Low & 62.5 & 30 & 4.17 & 2 & 60.42 & 29 & 60.42 & 29 \\
\hline \multirow{4}{*}{ Cognitive } & High & 4.17 & 2 & 22.92 & 11 & 2.08 & 1 & 2.08 & 1 \\
\hline & Sufficient & 4.17 & 2 & 62.5 & 30 & 4.17 & 2 & 4.17 & 2 \\
\hline & Average & 29.16 & 14 & 12.5 & 6 & 31.25 & 15 & 33.33 & 16 \\
\hline & Low & 62.5 & 30 & 2.08 & 1 & 62.5 & 30 & 60.42 & 29 \\
\hline \multirow{4}{*}{ Operational } & High & 4.16 & 2 & 25 & 12 & 2.08 & 1 & 2.08 & 1 \\
\hline & Sufficient & 6.25 & 3 & 62.5 & 30 & 6.25 & 3 & 6.25 & 3 \\
\hline & Average & 31.25 & 15 & 10.42 & 5 & 33.33 & 16 & 35.42 & 17 \\
\hline & Low & 58.34 & 28 & 2.08 & 1 & 58.34 & 28 & 56.25 & 27 \\
\hline
\end{tabular}

The dynamics of preparedness in terms of the motivational and value-based component in the CG is much lower in comparison to EG. The graphic interpretation of results prior to and following the experiment are presented in Figure 1.

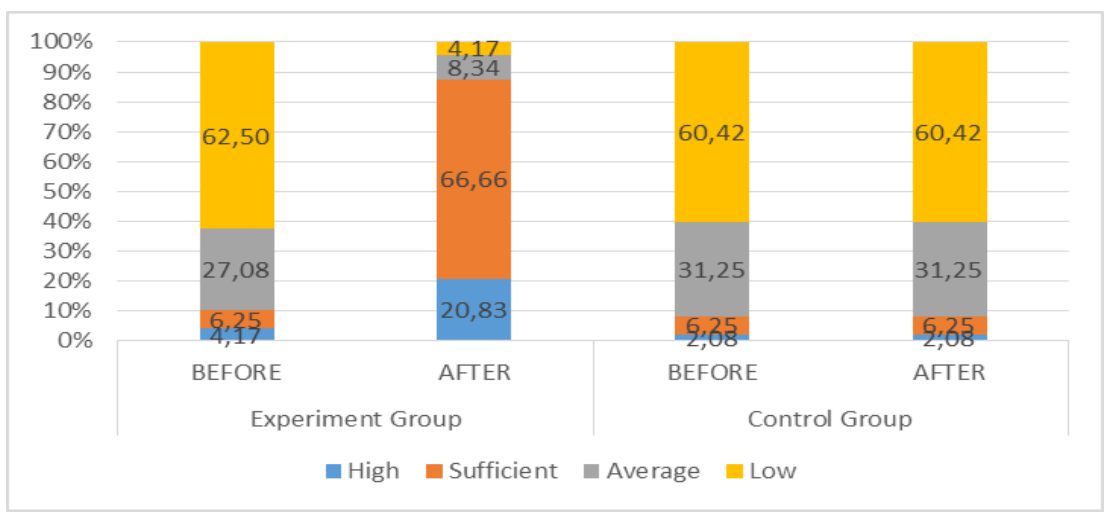

Figure 1

The status of teachers' preparedness for tutor activities by maturity levels of the motivational and value-based component (final assessment, \%) 
The next performance indicator of the research and experiment work we considered were positive changes with regard to the levels of preparedness of EG teachers for tutor activities in terms of the cognitive component.

As was the case with studying the motivational and value-based component of preparedness for tutor activities in higher educational institutions of 3rd-4th accreditation level, we observe significant dynamics under the cognitive component within EG compared to CG.

The analysis of data from Table 1 demonstrated that upon the implementation of a respective model $2.08 \%$ of EG teachers have nearly zero knowledge of the theoretical foundations of DL. However, the number of teachers with the sufficient level of preparedness (EG - 62.5\% compared to $4.17 \%$ in $\mathrm{CG}$ ) and high level of preparedness (22.92\% in EG against $2.08 \%$ in CG) increased considerably.

Statistical data of initial and final evaluation based on the cognitive component have clearly demonstrated that the model we implemented is rather efficient. The quantitative findings of the research before and after the experiment are presented in Figure 2.

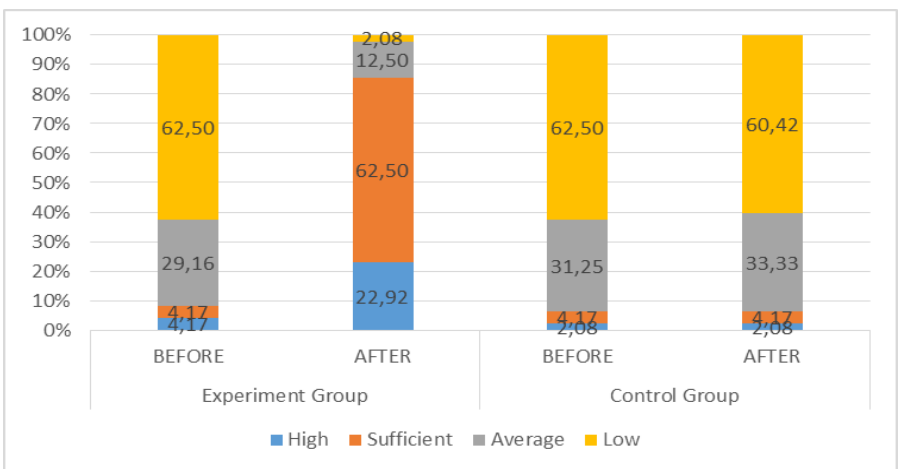

Figure 2

The status of teachers' preparedness for tutor activities by maturity levels of the cognitive component (final assessment, \%)

The study of the status of teachers' preparedness for tutor activities by maturity levels of the operational component attested to the increase of the number of respondents with sufficient and high levels. This is attested to by the consolidated data presented in Table 1 .

Thus, EG teachers, following the implementation of the respective model, not only deepened their knowledge and improved skills in utilizing different forms and methods of DL arrangement in a higher educational institution, but also learned to work in the information and education environment of Pavlo Tychyna State Pedagogical University of Uman (http://dls.udpu.org.ua). According to data analysis, the number of teachers with the sufficient level of preparedness (EG $-62.5 \%$ compared to $6.25 \%$ in $\mathrm{CG}$ ) and high level of preparedness (25\% in EG against $2.08 \%$ in $\mathrm{CG}$ ) increased considerably.

The histogram presented in Figure 3 reflects the dynamics of teachers' prepared for tutor activities by maturity levels of the operational component before and after the experiment. 


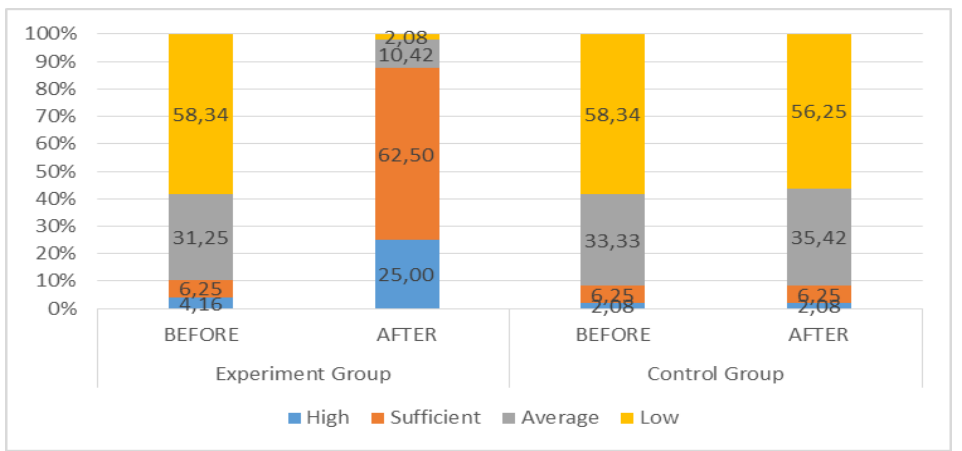

Figure 3

The status of teachers' preparedness for tutor activities by maturity levels of the operational component (final assessment, \%)

Therefore, the results of the pedagogic experiment have demonstrated that based on the motivation and value-based component of preparedness, almost all EG teachers' attitude to the issue of DL organization in higher educational institutions of 3rd-4th accreditation level and organizing continuing education changed for the better. Correspondingly, based on the cognitive indicator of preparedness, EG teachers formed durable knowledge of the theory of DL, the use and development of DL technologies in work with students, as well as organizing continuing education. Based on the operational indicator of preparedness, necessary knowledge and DL technology development and implementation skills for the respective functional competence.

Data presented in Table 1 and Figures 1-3 manifest the advantage of the high and sufficient preparedness level for tutor activities of EG teachers based on all the defined components, which attests to the efficiency of implementing teacher-tutor (organizer) training methodologies in higher educational institutions of 3rd-4th accreditation level.

The overall level of teachers' preparedness for tutor activities in higher educational institutions of 3rd4th accreditation levels was checked and calculated as the arithmetic mean of all criteria. The final maturity level of teachers' preparedness for tutor activities was determined. The generalized findings of the experiment are consolidated in Table 2, and the graph interpretation is shown in Figure 4.

Table 2

The overall level of teachers' preparedness for tutor activities in higher educational institutions of 3rd4th accreditation levels (final assessment)

\begin{tabular}{lllllllll}
\hline & \multicolumn{4}{c}{ Experiment Group } & \multicolumn{3}{c}{ Control Group } \\
\cline { 2 - 10 } Preparedness Levels & \multicolumn{3}{c}{ BEFORE } & \multicolumn{2}{c}{ AFTER } & \multicolumn{2}{c}{ BEFORE } & \multicolumn{2}{c}{ AFTER } \\
\cline { 2 - 10 } & q-ty & absolute & q-ty & absolute & q-ty & absolute & q-ty & absolute \\
& in \% & q-ty & in $\%$ & q-ty & in \% & q-ty & in \% & q-ty \\
\hline High & 4.17 & 2 & 22.92 & 11 & 2.08 & 1 & 2.08 & 1 \\
Sufficient & 6.25 & 3 & 64.58 & 31 & 6.25 & 3 & 6.25 & 3 \\
Average & 29.16 & 14 & 10.42 & 5 & 31.25 & 15 & 33.33 & 16 \\
Low & 60.42 & 29 & 2.08 & 1 & 60.42 & 29 & 58.34 & 28 \\
\hline
\end{tabular}




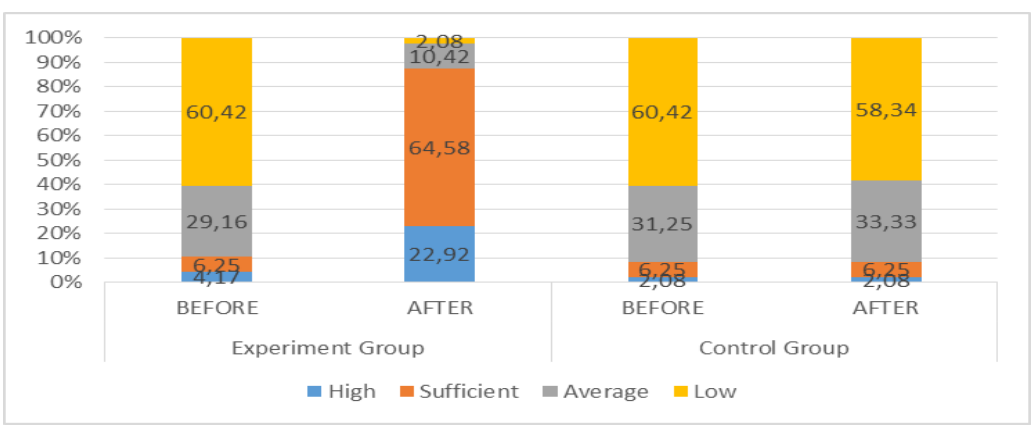

Figure 4

The overall level of teachers' preparedness for tutor activities in higher educational institutions of 3rd4th accreditation levels (final assessment, \%)

The efficiency of the training methodology to secure EG teachers' preparedness for tutor activities is attested to by the efficiency component that was calculated under the following formula:

$\mathrm{K}=$ Rafter / Rbefore,

where Rafter is the average, sufficient and high indicator of preparedness of teachers for tutor activities in the aftermath of the experiment (percentagewise);

Rbefore is the average, sufficient and high indicator of preparedness of teachers for tutor activities prior to the experiment (percentagewise);

One can speak about the efficiency of the designed model in the case when $\mathrm{K}>1$.

In our study, $\mathrm{K}=95.83$ / $37.5 \approx 58.33$ (motivational and value-based preparedness component);

$\mathrm{K}=97.92 / 37.5 \approx 60.42$ (cognitive);

$\mathrm{K}=97.92 / 41.66 \approx 56.26$ (operational);

$\mathrm{K}=97.92 / 39.58 \approx 58.34$ (overall preparedness level);

The final stage of the experiment has demonstrated that the overwhelming majority of EG teachers ascended to a higher level of preparedness to tutor activities. Based on the results of the statistical processing of participants' questionnaires, a significant increase was noted of the parameters of the indicators of all levels measured.

The data attest to the efficiency of the proposed methodology of the training of teachers-tutors (organizers) in DL within the higher educational institutions of 3rd-4th accreditation levels.

For the final statistical verification of the high performance of the experiment, it is necessary to compare the experimental data of EG and CG, having calculated the Pearson's criterion based on the data in respect of the motivational and value-based, cognitive, operational components and the overall level of preparedness. The empirical value of criteria equals approximately to $61.27,63.51,62.08$, 62.29 , which exceeds the critical value $\chi_{\text {crit. }}{ }^{2}=7.81$ for the degree of variance $v=3$ and $\alpha=0.05$. The discrepancies between EG and CG can be considered verifiable.

Therefore, the effectiveness of the proposed methodology was statistically proven; the methodology can be used to form the motivational and value-based, cognitive and operations constituents of teachers' preparedness for tutor activities in higher educational institutions of 3rd-3th accreditation levels was checked. 
The experimental model has proved to be effective and gives grounds to continue work on the improvement of the professional competence of present-day teachers of pedagogic higher educational institutions and to replicate the experience that we have gained.

On the next stage of the study, the methodology of securing primary school teachers' preparedness for DL within the system of lifelong education was implemented (throughout the academic years from 2014 to 2016).

Overall, 423 respondents from seven educational institutions participated in the experiment, of which: 342 are students doing training on the Elementary Education domain and 81 elementary school teachers.

In the course of the formal experiment, the training process in the EG was performed in the conventional manner, within the curricula of higher educational institutions and differed from that of CG in terms of the mastery of the study subject titled The Fundamentals of Distant Learning in elementary education (O. P. Mukoviz, 2014a).

In order to assess the performance of the model of DL implementation in the system of lifelong education of elementary school teachers, a forming experiment was conducted with the aim of checking high-performance changes in maturity levels of the motivational-value based, cognitive and operational components of primary school teachers' preparedness for DL within the system of lifelong education. This verification can be formed on the basis of qualimetric indicators aligned with the questions from our survey. Based on the responses given in the participant questionnaires at the forming stage of the experiment, their score was counted. The results of this activity are presented in Table 3.

Table 3

The status of primary school teachers' preparedness for DL within the system of lifelong education by component maturity levels (final assessment)

\begin{tabular}{|c|c|c|c|c|c|c|c|c|c|}
\hline \multirow{3}{*}{$\begin{array}{l}\text { Preparedness } \\
\text { Element }\end{array}$} & \multirow{3}{*}{$\begin{array}{l}\text { Preparedness } \\
\text { Levels }\end{array}$} & \multicolumn{4}{|c|}{ Experiment Group } & \multicolumn{4}{|c|}{ Control Group } \\
\hline & & \multicolumn{2}{|c|}{ BEFORE } & \multicolumn{2}{|c|}{ AFTER } & \multicolumn{2}{|c|}{ BEFORE } & \multicolumn{2}{|c|}{ AFTER } \\
\hline & & $\begin{array}{l}\text { q-ty } \\
\text { in } \%\end{array}$ & $\begin{array}{l}\text { absolute } \\
\text { q-ty }\end{array}$ & $\begin{array}{l}\text { q-ty } \\
\text { in } \%\end{array}$ & $\begin{array}{l}\text { absolute } \\
\text { q-ty }\end{array}$ & $\begin{array}{l}\text { q-ty } \\
\text { in \% }\end{array}$ & $\begin{array}{l}\text { absolute } \\
\text { q-ty }\end{array}$ & $\begin{array}{l}\text { q-ty } \\
\text { in } \%\end{array}$ & $\begin{array}{l}\text { absolute } \\
\text { q-ty }\end{array}$ \\
\hline \multirow{4}{*}{$\begin{array}{l}\text { Motivational } \\
\text { and } \quad \text { Value- } \\
\text { Based }\end{array}$} & High & 1.88 & 4 & 9.39 & 20 & 1.91 & 4 & 1.43 & 3 \\
\hline & Sufficient & 7.05 & 15 & 15.02 & 32 & 7.62 & 16 & 7.62 & 16 \\
\hline & Average & 28.63 & 61 & 51.64 & 110 & 29.05 & 61 & 29.53 & 62 \\
\hline & Low & 62.44 & 133 & 23.95 & 51 & 61.42 & 129 & 61.42 & 129 \\
\hline \multirow{4}{*}{ Cognitive } & High & 1.88 & 4 & 4.69 & 10 & 1.91 & 4 & 1.91 & 4 \\
\hline & Sufficient & 6.58 & 14 & 13.14 & 28 & 7.15 & 15 & 7.62 & 16 \\
\hline & Average & 17.37 & 37 & 51.65 & 110 & 16.66 & 35 & 17.14 & 36 \\
\hline & Low & 74.17 & 158 & 30.52 & 65 & 74.28 & 156 & 73.33 & 154 \\
\hline \multirow{4}{*}{ Operational } & High & 2.35 & 5 & 10.33 & 22 & 2.38 & 5 & 2.38 & 5 \\
\hline & Sufficient & 8.92 & 19 & 23.95 & 51 & 9.52 & 20 & 9.52 & 20 \\
\hline & Average & 39.91 & 85 & 51.64 & 110 & 39.53 & 83 & 40 & 84 \\
\hline & Low & 48.82 & 104 & 14.08 & 30 & 48.57 & 102 & 48.1 & 101 \\
\hline
\end{tabular}

The analysis of data in terms of the motivational and value-based component shows that $23.95 \%$ of EG teachers lack a lasting cognitive interest in DL in lifelong education system; these teachers do not understand the advantages that DL technologies deliver to them compared to traditional teaching methods. Moreover, they are not endeavoring to capitalize on modern opportunities of LD in organizing their professional activities. However, the number of teachers with the average level of preparedness (EG $-51.64 \%$ compared to $29.53 \%$ in $C G)$ and sufficient level of preparedness $(15.02 \%$ in EG against $7.62 \%$ in $\mathrm{CG}$ ) increased considerably. 
The dynamics of preparedness in terms of the motivational and value-based component in the CG is much lower in comparison to EG. The graphic interpretation of results prior to and following the experiment are presented in Figure 5.

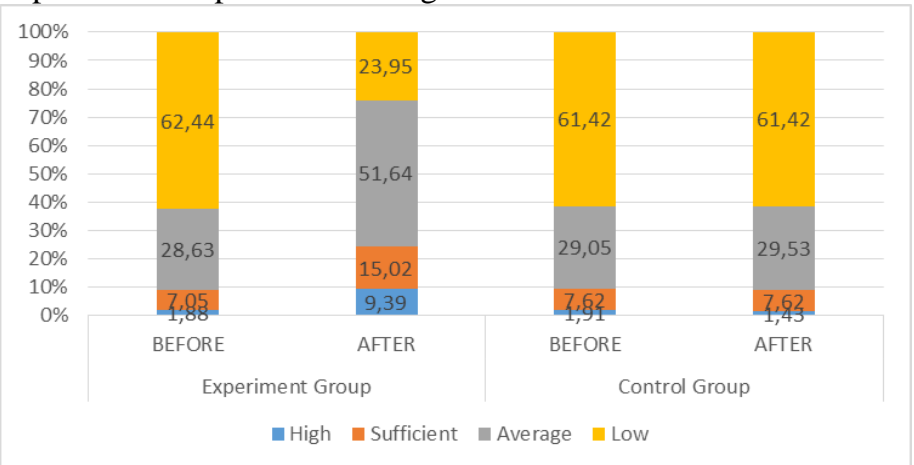

Figure 5

The status of primary school teachers' preparedness for DL within the system of lifelong education by the maturity level of the motivational and value-based component (final assessment, percentagewise)

The next performance indicator if the research and experimental work that we incorporated were positive changes in maturity levels of primary school teachers' preparedness for DL within the system of lifelong education by cognitive component maturity levels.

As was the case with studying the motivational and value-based component of elementary school teachers' preparedness for tutor activities in continuing educational system, we observe significant dynamics under the cognitive component within EG compared to CG.

The analysis of data from Table 3 demonstrates that upon the implementation of a respective methodology $30.52 \%$ of EG teachers had a low level of cognitive component maturity. However, the number of teachers with the average level of preparedness (EG - 51.65\% compared to $17.14 \%$ in $\mathrm{CG}$ ) and sufficient level of preparedness (13.14\% in EG against $7.62 \%$ in CG) increased considerably.

Statistical data of initial and final assessment based on the cognitive component have clearly demonstrated that the model we implemented is rather efficient. The quantitative findings of the research before and after the experiment are presented in Figure 6.

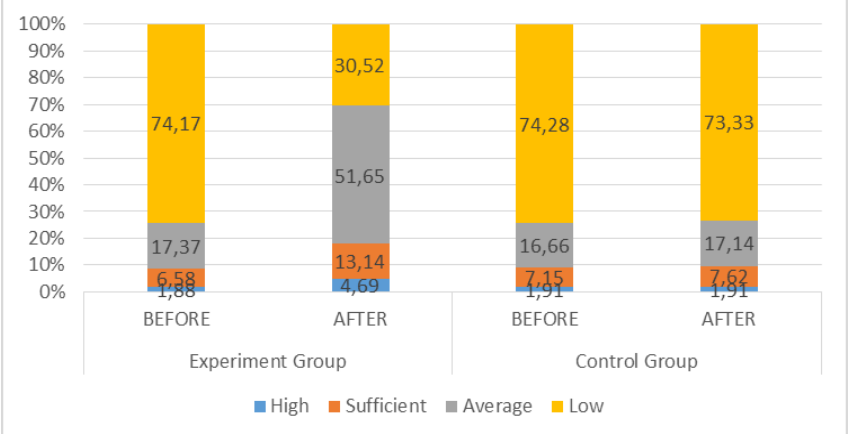

Figure 6

The status of primary school teachers' preparedness for DL within the system of lifelong education by cognitive component maturity levels (final assessment, percentagewise) 
The study of the status of elementary school teachers' preparedness for DL in lifelong education system by maturity levels of the operational component attested to the increase of the number of respondents with average, sufficient and high levels. This is attested to by the consolidated data presented in Table 3.

Thus, EG teachers, following the implementation of the respective methodology, not only deepened their knowledge and improved skills in utilizing different DL technologies, but also learned to work in the information and education environment (http://dls.udpu.org.ua) and in the lifelong education system of elementary school teachers (http://sno.udpu.org.ua) of Pavlo Tychyna State Pedagogical University of Uman (http://dls.udpu.org.ua).

Based on data analysis, the number of teachers with the average level of preparedness (EG $-51.64 \%$ compared to $40 \%$ in CG) and sufficient level of preparedness (23.95\% in EG against $9.52 \%$ in $\mathrm{CG}$ ) increased considerably. However, the low level accounts for $14.08 \%$ with EG and for $48.1 \%$ with CG. This points to the presence of experience of working with DL platforms in elementary school teachers.

The histogram presented in Figure 7 reflects the dynamics of elementary school teachers' prepared for DL in lifelong education system by maturity levels of the operational component before and after the experiment.

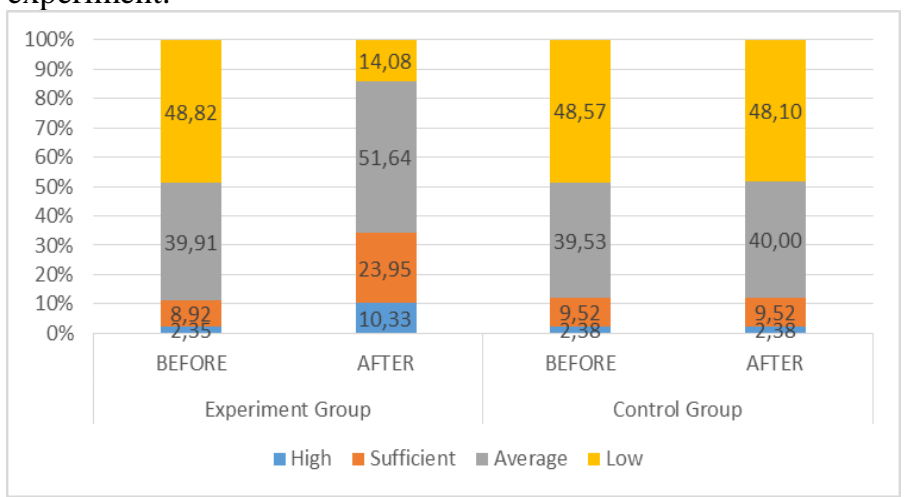

Figure 7

The status of primary school teachers' preparedness for DL within the system of lifelong education by operational component maturity levels (final assessment, percentagewise)

Therefore, the results of the pedagogic experiment have demonstrated that based on the motivation and value-based component of preparedness, almost all EG teachers' attitude to the issue of organizing DL in higher educational institutions and in lifelong education system changed for the better. Correspondingly, based on the cognitive indicator of preparedness, EG teachers formed durable knowledge of the theory of DL, the use and development of DL technologies in higher educational institutions and in the lifelong education system. Based on the operational indicator of preparedness, necessary knowledge and DL technology development and implementation skills for the respective functional competence were formed in higher educational institutions and in lifelong education system.

Data presented in Table 3 and Figures 5-7 manifest the advantage of the average and sufficient preparedness level of elementary school teachers for DL in lifelong education system based on all the defined components, which attests to the efficiency of the implementation of the proposed model.

The overall level of preparedness of primary school teachers' preparedness for DL within the system of lifelong education was calculated as the mean of all criteria under formula 2.

$\Sigma=\left(a_{1}+a_{2}+a_{2}\right): n$ 
where $\sum$ is the overall level of preparedness,

$a$ is the number of participants of the respective level in the preparedness component,

$n$ - number of preparedness components (motivational and value-based, cognitive an operational).

The final status of the maturity of primary school teachers' preparedness for DL within the system of lifelong education was determined. The generalized findings of the experiment are consolidated in Table 4, and the graph interpretation is shown in Figure 8.

Table 4

The overall level of primary school teachers' preparedness for DL within the system of lifelong education (final assessment)

\begin{tabular}{lllllllll}
\hline \multirow{2}{*}{$\begin{array}{l}\text { Preparedness } \\
\text { Levels }\end{array}$} & \multicolumn{3}{c}{ Experiment Group } & \multicolumn{3}{c}{ Control Group } \\
\cline { 2 - 11 } & $\begin{array}{l}\text { q-ty } \\
\text { in } \%\end{array}$ & $\begin{array}{l}\text { absolute } \\
\text { q-ty }\end{array}$ & $\begin{array}{l}\text { q-ty } \\
\text { in } \%\end{array}$ & $\begin{array}{l}\text { absolute } \\
\text { q-ty }\end{array}$ & $\begin{array}{l}\text { q-ty } \\
\text { in } \%\end{array}$ & $\begin{array}{l}\text { absolute } \\
\text { q-ty }\end{array}$ & $\begin{array}{l}\text { q-ty } \\
\text { in } \%\end{array}$ & $\begin{array}{l}\text { absolute } \\
\text { q-ty }\end{array}$ \\
\hline High & 2.04 & 4 & 7.98 & 17 & 1.91 & 4 & 1.91 & 4 \\
\hline Sufficient & 7.52 & 16 & 17.37 & 37 & 8.1 & 17 & 8.1 & 17 \\
\hline Average & 28.63 & 61 & 51.64 & 110 & 28.57 & 60 & 29.04 & 61 \\
\hline Low & 61.81 & 132 & 23.01 & 49 & 61.42 & 129 & 60.95 & 128 \\
\hline
\end{tabular}

The efficiency of the DL model within the system of lifelong education of primary school teachers is attested to by the performance indicator that was calculated under formula 1.

In our study, $K=76.05 / 37.56 \approx 38.49$ (motivational and value-based preparedness component);

$\mathrm{K}=69.48 / 25.83 \approx 43.65$ (cognitive);

$\mathrm{K}=85.92 / 51.18 \approx 34.74$ (operational);

$\mathrm{K}=76.99 / 38.19 \approx 38.8$ (overall preparedness level).

Data point to the efficiency of the DL model within the system of lifelong education of primary school teachers that we have designed.

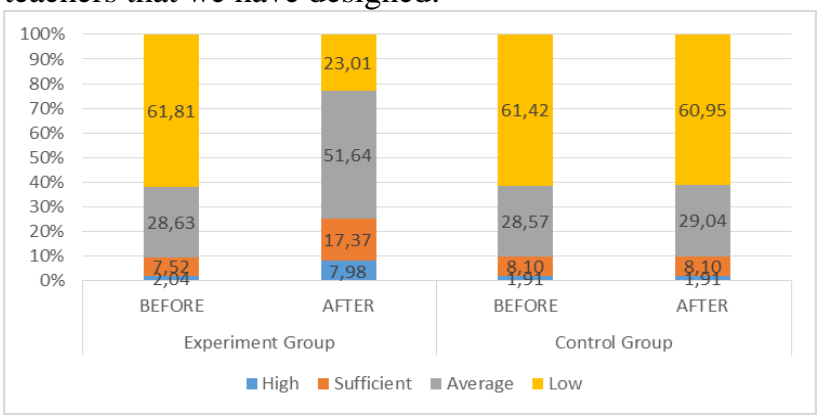

Figure 8

The general characteristic the levels of primary school teachers' preparedness for DL within the system of lifelong education (final assessment, percentagewise)

For the final statistical verification of the high performance of the experiment, it is necessary to compare the experimental data of EG and CG, having calculated the Pearson's criterion based on the data in respect of the motivational and value-based, cognitive, operational components and the overall level of preparedness. The empirical value of criteria equals approximately to $65.07,79.50,66.18$, 64.73 , which exceeds the critical value $\chi_{\text {crit. }}{ }^{2}=7.81$ for the degree of variance $v=3$ and $\alpha=0.05$. The discrepancies between EG and CG can be considered verifiable. 


\section{CONCLUSION}

Therefore, the pedagogic experiment that involved 423 elementary school teachers from seven educational institutions has attested to the efficiency of the designed DL model in lifelong education system.

The final stage of the experiment has demonstrated that the overwhelming majority of elementary school teachers ascended to a higher level of preparedness to DL in lifelong education system. Based on the results of the statistical processing of participants' questionnaires, a significant increase was noted of the parameters of the indicators of all levels measured.

Further research is necessary into defining the level of maturity of professional and pedagogic competence of primary school teachers in the context of DL within the system of lifelong education.

\section{REFERENCES}

Bykov, V. Yu. (2008). Models of the organization of an open education system: a monograph. Kyiv, K: Atika.

Kartashova, L. A. (2011). System of information technology teaching of future teachers of socialhumanitarian subjects. Lutsk: Volynpoligraph.

Kukharenko, V. M. (2012). On the system of distance education in an open distance course. Information technologies in education, 11, 32-42.

Mukoviz ,O. P. (2014). Designing of the Model of Distance Education in the System of Continuous Training of Primary School Teachers. Information Technologies and Learning Tools, 3, 209-217. Retrieved from http://journal.iitta.gov.ua/index.php/ittl/article/view/1053\#.U7O66G13psw

Mukoviz, O. P. (2014). The Course "Fundamentals of Distance Learning in Primary Education" as a Component of Lifelong Education of Primary School Teachers. Informational Technologies in Education, 20, 66-73. Retrieved from http://ite.kspu.edu/issue-20/

Mukoviz, O. P. (2014). Training of a Lecturer to Organization of Distant Education in the System of Continuous Education of Primary School Teachers. The Computer at School and Family, 6, 26-30.

Mukoviz, O. P. (2015). The State of Lecturers' Readiness to Tutor Activity in Higher Educational Institutions of III - IV Accreditation Levels. Pedagogy and Psychology, 49, 220-233. Retrieved from http://journals.hnpu.edu.ua/ojs/psyped/article/view/2774

Mukoviz, O. P. (2016). The Examination of Readiness of Primary School Teachers to Distance Learning in the System of Lifelong Education. GLOKALde, 1, 27-44. Retrieved from http://www.glokalde.com/pdf/issues/5/Article1.pdf.

Semerikov, S. O., Teplytskyi, I. O., \& Shokaliuk, S. V. (2008). New means of distance education to teach information technologies of mathematical purpose. Bulletin. Testing and monitoring in education, 2, 42-50.

Spirin, O. M., \& Kolos, K. R. (2011). Pedagogical experiment in the development of subject competencies of computer science teachers through distance education. Information technologies and teaching aids, 5 (25). Retrieved from http://journal.iitta.gov.ua/index.php/itlt/ article/view/555/446.

Spivakovskyi, O. V., Lvov, M. S., \& Kravtsov, H. M. (2009). Purposes and tasks of the project "Creation of the bank of electronic documents in distance education for higher pedagogical education". Information technologies in education, 4, 96-110. 